\title{
Relational Agency: Yes-But How Far? Vulnerability and the Moral Self
}

\section{Nicolae Morar \& Joshua August Skorburg}

To cite this article: Nicolae Morar \& Joshua August Skorburg (2017) Relational Agency: Yes-But How Far? Vulnerability and the Moral Self, AJOB Neuroscience, 8:2, 83-85, DOI: 10.1080/21507740.2017.1326409

To link to this article: http://dx.doi.org/10.1080/21507740.2017.1326409

册 Published online: 16 Jun 2017.

Submit your article to this journal $\pi$

Џll Article views: 17

Q View related articles $₫$

View Crossmark data $\asymp$ 
offer windows of opportunity to improve the engineering of closed-loop devices, making design choices (e.g., fully automated AP versus an AP that allows some input from the user) that would be informed by a contextual understanding of agency and identity.

\section{ACKNOWLEDGMENTS}

We thank Audrey Francoeur for editorial assistance. We also thank Dr. Rémi Rabasa-Lhoret and Virginie Messier for their helpful comments on this article.

\section{FUNDING}

Writing of this paper was supported by a career award from the Fonds de recherche du Québec-Santé (Eric Racine), a grant from the Canadian Institutes of Health Research and Fonds de recherche du Québec-Santé in collaboration with ERANET: NEURON (Eric Racine), and a grant from the National Institute of Diabetes and Digestive and Kidney Diseases, NIH (Rémi Rabasa-Lhoret; 1 DP3 DK106930-01).

\section{REFERENCES}

Barnard, K. D., T. Wysocki, H. Thabit, et al., and Angela Consortium. 2015. Psychosocial aspects of closed- and open-loop insulin delivery: Closing the loop in adults with type 1 diabetes in the home setting. Diabetic Medicine 32(5):601-8. doi:10.1111/dme. 12706

Bergmann, T. O., A. Karabanov, G. Hartwigsen, A. Thielscher, and H. R. Siebner. 2016. Combining non-invasive transcranial brain stimulation with neuroimaging and electrophysiology: Current approaches and future perspectives. NeuroImage 140(October):419. doi:10.1016/j.neuroimage.2016.02.012

Fisher, L., W. H. Polonsky, D. M. Hessler, et al. 2015. Understanding the sources of diabetes distress in adults with type 1 diabetes. Journal of Diabetes and its Complications 29(4):572-77. doi:10.1016/ j.jdiacomp.2015.01.012

Goering, S., E. Klein, D. Dougherty, and A. S. Widge. 2017. Staying in the loop: Relational agency and identity in next-generation DBS for psychiatry. AJOB Neuroscience 8(2):59-70.

Gonder-Frederick, L., J. Shepard, and N. Peterson. 2011. Closedloop glucose control: Psychological and behavioral considerations. Journal of Diabetes Science and Technology 5(6):1387-95. doi:10.1177/ 193229681100500610

Mathieu, G., E. Bell, and E. Racine. 2011. Subjective outcomes measurement and regulatory oversight for deep brain stimulation outcomes in Parkinson's disease. AJOB Neuroscience 2(1):16-18. doi:10.1080/21507740.2010.537535

Racine, E., O. Bar-Ilan, and J. Illes. 2005. fMRI in the public eye. Nature Reviews Neuroscience 6(2):159-64. doi:10.1038/nrn1609

Roskies, A. 2002. Neuroethics for the new millenium. Neuron 35(1):21-23. doi:10.1016/S0896-6273(02)00763-8

Shah, V. N., A. Shoskes, B. Tawfik, and S. K. Garg. 2014. Closedloop system in the management of diabetes: Past, present, and future. Diabetes Technology \& Therapeutics 16(8):477-90. doi:10.1089/dia.2014.0193

U.S. Food and Drug Administration. 2016. The artificial pancreas device system. Available at: https:/ /www.fda.gov/medicaldevices/ productsandmedicalprocedures / homehealthandconsumer/ consumerproducts/artificialpancreas/default.htm (accessed March 24, 2017).

Vidal, F. 2009. Brainhood, anthropological figure of modernity. History of the Human Sciences 22(1):5-36. doi:10.1177/0952695108099133

\title{
Relational Agency: Yes-But How Far? Vulnerability and the Moral Self
}

\author{
Nicolae Morar, University of Oregon \\ Joshua August Skorburg, University of Oregon
}

Goering, Klein, Dougherty, and Widge (2017) have done an important service in bringing feminist philosophical theories of self, identity, autonomy, and agency into a meaningful dialogue with the bioethical debates surrounding the next generation of therapeutic neuroprosthetics. We share many of the theoretical commitments expressed by the authors, and we are broadly sympathetic to their project (Morar and Skorburg 2016; Beever and Morar 2016; Kelly and Morar 2016; Alfano and Skorburg 2017). We agree that relational models provide powerful theoretical frameworks for understanding the many ways in which agents

Author names are listed in alphabetical order, which reflects equal contribution to the authorship of the article.

Address correspondence to Nicolae Morar, Department of Philosophy \& the Environmental Studies Program, 1295 University of Oregon, University of Oregon, Eugene, OR 97403, USA. E-mail: nmorar@uoregon.edu 
opportunistically incorporate features of the external environment (including props, tools, other people, etc.) to bolster their capabilities. Still, we perceive two significant shortcomings in their argument: (1) the authors fail to properly highlight the sense of vulnerability entailed by their view of relational agency and (2) the authors do not fully appreciate the potential threats to personal identity entailed by their view. We unpack each of these worries in an effort to strengthen the authors' argument.

\section{RELATIONAL AGENCY AND MORAL VULNERABILITY}

With respect to (1), we first want to make explicit an argumentative structure that is left largely implicit in the article. To illustrate, consider the authors' claim: "Just as our friends may be supporting or controlling of our agency, so too can neural devices be enhancing or threatening to our agency" (67). Roughly, the argument form is as follows: $X$ and $Y$ are-by a coarse-grained functional descriptionsimilar, so if $X$ is morally permissible, then $Y$, owing to the relevant functional parity, should be similarly morally permissible.

We contend that it is irresponsible to make this inference from functional parity to moral permissibility without acknowledging the profound sense of vulnerability required to get the argument from functional parity off the ground in the first place. We worry that the authors have not fully appreciated the cost at which their relational view is purchased. That is, any relational conception of agency or autonomy creates as much of a possibility for empowerment as disempowerment. To say that friends or prosthetics can scaffold and enhance our autonomy is to acknowledge that autonomy is fundamentally porous (Beever and Morar 2016). However, a responsible bioethical analysis must strive to articulate the full complexity of the concept of vulnerability and the ways in which it tracks not only our physical needs as a function of our embodiment (e.g., openness to injury, disability, etc.), but also our emotional and psychological vulnerability to others (e.g., lack of care, rejection, humiliation) and our social vulnerability to exploitation, manipulation, and oppression (Mackenzie, Rogers, and Dodds 2014; Straehle 2016).

By virtue of this openness and vulnerability, supportive, caring friends and well-designed prosthetics can yield highly desirable outcomes and boost our agential capacities. Indeed, Klein et al. (2016) report that many patients undergoing deep brain stimulation (DBS) for depression describe opportunities to experience a more authentic self and a wider range of feelings. One participant in their study reports, "I still like the same things. I don't have, like, different values or anything. I just enjoy things more. I'm me without depression" (144). The moral permissibility of such procedures, however, cannot be evaluated solely in light of successful outcomes without understanding the ways in which these very outcomes are underwritten by a view of the self as vulnerable-that is, open to modulation by DBS. This very same openness, after all, leads another participant to report feeling artificial: "I've begun to wonder what's me and what's the depression, and what's the stimulator" (144).

We worry, then, that the authors have not fully acknowledged the connection between relationality and vulnerability: the very same features that enable the therapeutic, autonomy-enhancing benefits of DBS also render the agent vulnerable to nontherapeutic and autonomyundermining harms. The concept of relationality is not a magic bullet, and its potential benefits must be carefully weighed against the potential harms it enables. When the issue is the moral permissibility of next-generation DBS devices, we think that the vulnerability of the agent is not a mere corollary of a metaphysical claim about individuals and autonomy, but rather, as many feminist bioethicists have insisted, the very locus of the debate. Moreover, the moral permissibility for such devices should never be evaluated with respect to a single variable (e.g., physical empowerment) but always in relation to the complex constellation of vulnerability including potential psychological and social disempowerment. To ignore the role of vulnerability in the present context is to ignore what is at once most promising and most troubling about closedloop DBS implants.

\section{DBS AND THE MORAL SELF}

With respect to (2), we are similarly worried that the authors have not seriously appreciated the difficulties of their preferred view of personal identity, especially when it comes to potentially altering a central piece of who we are: our moral self. The authors appeal to a loose-knit family of philosophical theories of identity, variously described as relational, dynamic, and narrative. The thread that ties them together is a kind of anti-essentialism about personal identity, exemplified in the authors' claims that "perhaps that vision of an essential self is itself suspect," and "we don't have essential traits (without which we would no longer be)" (62). These views surely have their own merits (and we are particularly sensitive in our work to these merits), not the least of which is their role in the argument from functional parity: if personal identity is always in flux, then the changes to personal identity from DBS might not be all that different from the changes to personal identity encountered in everyday social interactions.

We contend, however, that these anti-essentialist views face a potential challenge from some recent work in experimental moral psychology (Strohminger and Nichols 2014; 2015; Heiphetz, Strohminger, and Young 2016) that suggests there are indeed some features of the self which are perceived to be more "necessary" — and not merely more stable - than others. In a number of studies across a variety of contexts, Strohminger and colleagues have shown that one's morality or one's set of moral beliefs is consistently perceived as more identity-conferring than things like one's memories, preferences, or desires. In other words, 
changes to one's moral compass (e.g., from a generous to stingy disposition, or from racist to egalitarian beliefs) are perceived to be the most disruptive to personal identity. To be clear, our claim is emphatically not that such experimental work reveals the ontological basis of personal identity. It is doubtful that any empirical evidence could do that. Instead, our claim is that insofar as relational and narrative views claim that perceptions of the self by others are constitutive of personal identity, then this research on the essential moral self does reveal aspects of personal identity that are particularly relevant to the present debate. If closed-loop DBS poses a threat to personal identity, this threat will be amplified when aspects of the moral self are at stake. We thus disagree with the authors' contention that there is a "difficulty in ascertaining what would indeed constitute a threat to identity" (62). The robust research on the essential moral self offers a highly plausible criterion for what counts as a threat to personal identity: if changes to the moral self are seen as particularly disruptive to personal identity, then it is precisely undue changes in this domain that we should be most worried about.

In general (though they are writing in the context of neurodegenerative disease), we concur with Strohminger and Nichols that "future therapies ought to be aimed atand take into account-preserving moral function, a previously unappreciated factor in the well-being of patients and their families" (2015, 1477, emphasis ours). More specifically, we think that studies like those described by Klein et al. (2016) would do well to include survey items about potential changes to the moral self.

\section{FUTURE DIRECTIONS}

By way of conclusion, we believe the two shortcomings we have identified also hint at directions for future work. Recall the case, drawn from Klein et al. (2016), of the participant who attended a funeral after having her open-loop DBS device programmed. While the authors couch this case in debates about agency, we believe it actually reveals the importance of taking seriously the psychological dimension of vulnerability described in our first section and the threat to the moral self described in our second section. After all, feeling the right emotions, in the right degree, for the right amount of time, and so on, is a crucial aspect of anyone's moral life.

We believe that any future conversation about the epistemic and moral benefits of relational conceptions of humanity (that helps us understand how human beings can reliably integrate external resources into their own agency) must be predicated on the two aspects this view entails: empowerment and vulnerability, and the various trade-offs between the complex variables that inform a more comprehensive sense of our human fragility.

\section{REFERENCES}

Alfano, M., and J. A. Skorburg. 2017. The embedded and extended character hypotheses. In The Routledge handbook of philosophy of the social mind, ed. J. Kiverstein, 465-78. New York, NY: Routledge

Beever, J., and N. Morar. 2016. The porosity of autonomy: Social and biological constitution of the patient in biomedicine. American Journal of Bioethics 16(2):34-45.

Goering, S., E. Klein, D. Dougherty, and A. Widge. 2017. Staying in the loop: Relational agency and identity in next-generation DBS for psychiatry. AJOB Neuroscience 8(2):59-70.

Heiphetz, L., N. Strohminger, and L. L. Young. 2016. The role of moral beliefs, memories, and preferences in representations of identity. Cognitive Science 41(3):744-67. doi:10.1111/cogs.12354.

Kelly, D., and N. Morar. 2016. Nudging and the ecological and social roots of human agency. American Journal of Bioethics 16(11):15-17

Klein, E., S. Goering, J. Gagne, et al. 2016. Brain-computer interface-based control of closed-loop brain stimulation: Attitudes and ethical considerations. Brain-Computer Interfaces 3(3):140-48.

Mackenzie, C., W. Rogers, and S. Dodds, eds. 2014. Vulnerability: New essays in ethics and feminist philosophy. Oxford, UK: Oxford University Press.

Morar, N., and J. A. Skorburg. 2016. Toward an ecological bioethics. American Journal of Bioethics 16(5):35-37.

Straehle, C., ed. 2016. Vulnerability, autonomy, and applied ethics. New York, NY: Routledge.

Strohminger, N., and S. Nichols. 2014. The essential moral self. Cognition 131:159-71.

Strohminger, N., and S. Nichols. 2015. Neurodegeneration and identity. Psychological Science 26(9):1469-79. 